\title{
ASSAY OF STAPHYLOCOCCAL $\delta$-HAEMOLYSIN WITH FISH ERYTHROCYTES
}

\author{
LIN-PO CHAO* AND T. H. BIRKBECK \\ Department of Microbiology, University of Glasgow, Alexander Stone Building, \\ Garscube Estate, Bearsden, Glasgow G61 1QH
}

\section{Plate XXVIII}

STAPHYLOCOCCUS AUREUS produces four haemolysins, $\alpha, \beta, \gamma$ and $\delta$, and they are differentiated by their lytic activity against erythrocytes of different animal species. For the assay of $\alpha$-haemolysin (Arbuthnott, 1970) and $\gamma$ haemolysin (Möllby and Wadström, 1971; Wiseman, 1975) rabbit erythrocytes are used because they are more sensitive than all others that have been tested. The $\beta$-haemolysin, a sphingomyelinase $\mathrm{C}$ (Doery et al., 1965) is assayed with sheep or bovine erythrocytes; they are particularly sensitive because of their high content of sphingomyelin (Nelson, 1967; Wiseman and Caird, 1967).

Delta-haemolysin has a much lower specific activity than the other haemolysins, and in low dilutions lyses a wide range of erythrocytes; it is usually assayed with human or horse erythrocytes and these have indicated as many as 300 haemolytic units per $\mathrm{mg}$ (HU per $\mathrm{mg}$ ) in purified preparations (Heatley, 1971; Kreger et al., 1971). Heatley (1971) found that $\beta$-haemolysin was capable of interfering with the assay of $\delta$-haemolysin when human erythrocytes were used. Lysis of bacterial protoplasts (Bernheimer et al., 1972) provides a more sensitive assay (610 units per $\mathrm{mg}$ ) but is less convenient when a large number of samples is screened. The release of radioactively labelled nucleotides from tissue-culture cells (Thelestam, Möllby and Wadström, 1973) also provides a sensitive assay (approximately 600 units per $\mathrm{mg}$ purified protein) in which interference by other haemolysins does not occur. The simple haemolytic assay is still routinely used for $\delta$-haemolysin, but a more specific and sensitive assay would be desirable. The work described here resulted from a preliminary survey of the sensitivity of marine fish erythrocytes to staphylococcal haemolysins and we describe the use of fish erythrocytes for the assay of staphylococcal $\delta$-haemolysin.

\section{MATERIALS AND METHODS}

Staphylococcal strains. Staphylococcus aureus strains NCTC10345 and NCTC7121 (Wood 46) were obtained from Professor J. P. Arbuthnott. The remainder, obtained from Dr S. McKay, comprised $S$. aureus strain BB, a $\beta$-toxinogenic bovine-mastitis isolate, and clinical isolates of $S$. aureus (strains SM9, SM10, SM14, JK21) and $S$. epidermidis (strain SM6). Cultures were maintained on nutrient agar slopes.

Received 17 Oct. 1977; revised version accepted 9 Jan. 1978.

* Present address: Department of Biochemistry, University of Glasgow, Glasgow G12 8QQ.

J. MED. MICROBIOL.-VOL. 11 (1978) 
Staphylococcal haemolysins. Purified $\alpha$-haemolysin (McNiven, Owen and Arbuthnott, 1972), and $\delta$-haemolysin prepared by Dr A. Kreger (Kreger et al., 1971), were obtained from Professor J. P. Arbuthnott. Purified $\beta$-haemolysin (Low and Freer, 1977) was a gift from Dr D. K. R. Low. Concentrated culture supernate of $S$. aureus Wood 46 was prepared by ammonium sulphate precipitation (McNiven et al., 1972).

Purification of $\delta$-haemolysin. Delta-haemolysin was purified from culture supernates of $S$. aureus NCTC10345 by the method of Kreger et al. (1971). Isoelectric focusing (Talbot and Caie, 1975) yielded a single peak of protein (pI 4.5$)$ that contained all the detectable haemolytic activity for cod, human and rabbit erythrocytes. In acidic polyacrylamide gels (Reisfeld, Lewis and Williams, 1962) a single broad band was formed and in alkaline gels (Davis, 1964) a broad band with a faint secondary band.

Haemolytic activity. Cod blood was obtained from fish freshly caught by trawling in the Firth of Clyde. Fish were anaesthetised by placing them in water containing Sandoz MS222, $0.01 \% \mathrm{w} / \mathrm{v}$ (Sandoz Ltd, Basle, Switzerland); blood withdrawn from the dorsal aorta with a syringe and needle and mixed with $3.8 \%(\mathrm{w} / \mathrm{v})$ sodium citrate was transported to the laboratory and stored in liquid nitrogen with dimethylsulphoxide as a cryoprotectant (Chao and Birkbeck, to be published). The cod erythrocytes were washed four times in citrate-dextrosesaline buffer (CDS) (Hodgins and Ridgway, 1964) and a $1 \%(\mathrm{v} / \mathrm{v})$ suspension was made in CDS and standardised spectrophotometrically (Rennie and Arbuthnott, 1974). Erythrocytes from fish other than cod were not stored in liquid nitrogen, but were washed and suspended in phosphate buffered saline (PBSA) (Dulbecco and Vogt, 1954). Preliminary experiments showed that cod erythrocytes stored in liquid nitrogen had the same sensitivity to $\delta$-haemolysin as those tested within $24 \mathrm{~h}$ of collection. Haemolytic activity was determined by making doubling dilutions of haemolysin $(0.5 \mathrm{ml})$ in $0.5-\mathrm{ml}$ aliquots of buffer (PBSA for mammalian erythrocytes and CDS for fish erythrocytes) and adding $0.5 \mathrm{ml}$ of $1 \%(\mathrm{v} / \mathrm{v})$ erythrocyte suspension. After $30 \mathrm{~min}$. at $37^{\circ} \mathrm{C}$ (mammalian erythrocytes) or $15^{\circ} \mathrm{C}$ (fish erythrocytes) the end-point ( $50 \%$-haemolysis) was determined spectrophotometrically. Activity was expressed as haemolytic units (HU50) per ml, i.e., as the dilution of haemolysin that caused release of $50 \%$ of the haemoglobin under the above assay conditions. Staphylococcal $\beta$-haemolysin was assayed as described by Low and Freer (1977). Saponin (BDH Chemicals Ltd, Poole, England) and Triton X-100 (Sigma Chemical Co., St Louis, Missouri, USA) were compared with $\delta$-haemolysin in haemolysis tests against different erythrocytes.

Radial diffusion assay. Plates were prepared by pouring $5 \mathrm{ml}$ of molten "blood agar" $(1-5 \%, \mathrm{v} / \mathrm{v}$, washed erythrocytes in Oxoid Blood Agar Base No. 2) into a 5-cm plastic Petri dish (Sterilin Ltd, Richmond, Surrey). Sodium azide (0.01\%) did not affect haemolysis by $\delta$-haemolysin and it was incorporated to inhibit bacterial growth; $0 \cdot 1 \mathrm{M} \mathrm{NaCl}$ was incorporated in addition in fish-erythrocyte agar to increase osmolality and to give clearer zones of lysis. Aliquots of a standard solution of $\delta$-haemolysin $(10 \mu \mathrm{l})$ were placed in wells of $3.5-\mathrm{mm}$ diameter cut in the blood agar, and the plates were incubated at $37^{\circ} \mathrm{C}$ for $24 \mathrm{~h}$ (human erythrocytes) or $4^{\circ} \mathrm{C}$ for $48 \mathrm{~h}$ (cod erythrocytes). The radius of the haemolytic zone was measured with an eyepiece containing a millimetre graticule.

Growth of S. aureus on blood agar-overlay plates. A stab inoculation technique described by Williams and Harper (1947) and Marks and Vaughan (1950) was used. Nutrient agar plates (9-cm diameter) were inoculated with each strain and incubated for $24 \mathrm{~h}$ at $37^{\circ} \mathrm{C}$. Overlays of $5 \mathrm{ml}$ of $5 \%(\mathrm{v} / \mathrm{v})$ " blood agar" containining washed erythrocytes and $0.01 \%$ sodium azide were added and the sizes of the haemolytic zones were measured after $24 \mathrm{~h}$ at $4^{\circ} \mathrm{C}$ unless stated otherwise.

\section{RESULTS}

\section{Specificity of the haemolytic reaction}

Concentrated culture supernates of $S$. aureus strain Wood 46, assayed with cod erythrocytes, showed no loss in titre after heating at $100^{\circ} \mathrm{C}$ for $10 \mathrm{~min}$., but such treatment reduced the titre to $<0.01 \%$ of its original value when rabbit 
TABLE I

Sensitivity of cod erythrocytes to staphylococcal haemolysins

\begin{tabular}{l|ccc}
\multicolumn{1}{c|}{ Staphylococcal haemolysin preparation } & \multicolumn{2}{c}{$\begin{array}{c}\text { Titres (HUS0 per ml) of haemolysins as shown } \\
\text { by assays with erythrocytes of the }\end{array}$} \\
\hline$\overbrace{\text { rabbit }}^{\text {cod }}$ & sheep \\
Healture filtrate (S. aureus, strain Wood 46) & 10000 & 320 & $\ldots$ \\
Purified $\alpha$-haemolysin & 80 & 320 & $\ldots$ \\
Purified $\beta$-haemolysin & 3200 & $<10$ & $\ldots$ \\
Purified $\delta$-haemolysin & $\ldots$ & $<10$ & $10^{6}$ \\
\hline
\end{tabular}

erythrocytes were used (table I). Purified $\alpha$ - and $\beta$-haemolysins were inactive against cod erythrocytes at the highest concentrations tested, whereas purified $\delta$-haemolysin was four times more active against cod erythrocytes than against rabbit cells (table I). No synergistic action was detected when mixtures of purified $\beta$ - and $\delta$-haemolysins were titrated against cod erythrocytes. The haemolytic activity of $\delta$-haemolysin against cod and rabbit erythrocytes was neutralised by normal human serum.

\section{Parameters of the haemolytic assay}

Incubation temperature. When cod erythrocytes were used for the assay of crude $\delta$-haemolysin preparations, and also when cod or mackerel erythrocytes were used for the assay of purified $\delta$-haemolysin, the haemolysin titres were virtually constant over the range $0-37^{\circ} \mathrm{C}$. However, all further titrations were carried out at $15^{\circ} \mathrm{C}$.

Time of incubation. The kinetics of lysis were determined from four parallel doubling-dilution assays which were terminated by centrifugation $(100 \mathrm{~g}$ for 5 min.) after 10, 20, 30 or $60 \mathrm{~min}$; the degree of lysis in each tube was measured spectrophotometrically. Cod erythrocytes are nucleated and the release of debris from lysed nuclei made the centrifugation necessary. Erythrocyte lysis was rapid and at the titration end-point the degree of lysis increased only slightly after incubation for $10 \mathrm{~min}$.

In all doubling-dilution assays the incubation time was $30 \mathrm{~min}$., although $10 \mathrm{~min}$. would have been adequate.

Composition and ionic strength of the diluent. No significant change in haemolysin titre was found on assay in PBSA, CDS, CDS with added $\mathrm{NaCl}$ $(2,4,6,8,10,12$ or $14 \mathrm{~g}$ per litre) or PBSA with added $\mathrm{NaCl}(2,4$ or $6 \mathrm{~g}$ per litre). 
Incubation with $1 \mathrm{~mm} 2$-mercaptoethanol did not increase haemolytic activity against cod erythrocytes.

Erythrocyte concentration. The haemolysin titre varied with the erythrocyte concentration. When the erythrocyte concentration was halved, the haemolysin titre increased approximately $1 \cdot 6$-fold. With $0.3 \%$ erythrocyte suspensions, end-points could be measured satisfactorily by spectrophotometry, but $0.5-1 \%$ cell suspensions were more suitable for visual estimations.

To study the action of $\delta$-haemolysin on erythrocytes in more detail, haemolysin, 1 HU50 (determined separately against $1 \%$ suspensions of human, cod and mackerel erythrocytes) was added to each of a number of different concentrations of human, cod and mackerel erythrocytes, and the percentage cell lysis after incubation for $30 \mathrm{~min}$. was determined spectrophotometrically. With fish erythrocytes, the percentage cell lysis was a linear function of log erythrocyte concentration, but for human erythrocytes a curve was obtained (fig. 1) indicating that, although $\delta$-haemolysin acts on a wide range of erythrocytes, erythrocytes of different species do not respond to $\delta$-haemolysin in the same way.

Within the range of erythrocytes tested, fish erythrocytes were invariably more sensitive than mammalian erythrocytes to $\delta$-haemolysin (table II). Mackerel erythrocytes showed the greatest sensitivity, being 16 times more sensitive than human or horse erythrocytes. No significant individual variation in the haemolysin sensitivity of erythrocytes was found in cod (12 fish) or saithe (four fish).

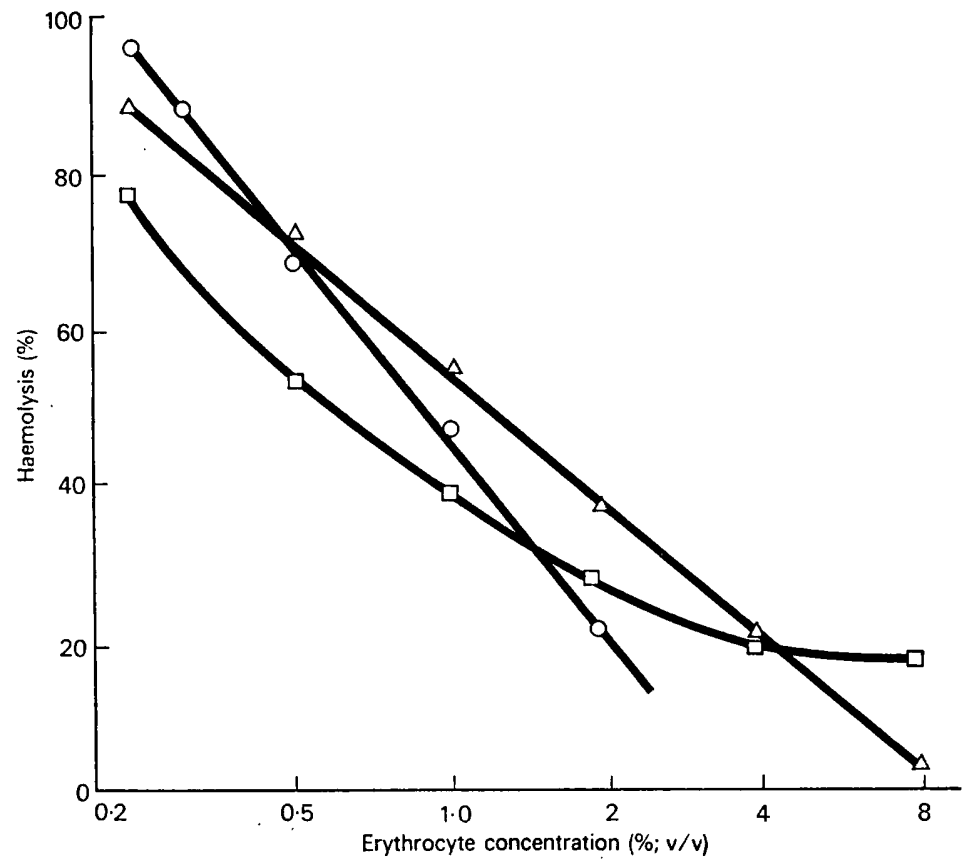

Fig. 1.-Degrees of haemolysis resulting from incubation of a fixed quantity of $\delta$-haemolysin with various concentrations of mackerel $(O-\longrightarrow)$, cod $(\triangle \longrightarrow-\triangle)$ and human $(\square-\square)$ erythrocytes. 
TABLE II

Haemolytic spectrum of staphylococcal $\delta$-haemolysin

\begin{tabular}{l|c}
\hline \multicolumn{1}{c}{$\begin{array}{c}\text { Species from which erythrocytes } \\
\text { obtained }\end{array}$} & $\begin{array}{c}\text { Sensitivity* of } \\
\text { erythrocytes to } \\
\delta \text {-haemolysin }\end{array}$ \\
\hline Man & 100 \\
Horse & 100 \\
Rabbit & 60 \\
Sheep & 20 \\
Cod (Gadus morhua) & 400 \\
Poor cod (Trisoplerus minutus) & 400 \\
Saithe (Pollachius virens) & 400 \\
Haddock (Melanogrannus aeglifinus) & 400 \\
Hake (Merluccius merluccius) & 400 \\
Whiting (Merlangius merlangus) & 400 \\
Plaice (Pleruonectes platessa) & 200 \\
Gurnard (Eutriglia gurnadus) & 200 \\
Mackerel (Scomber scombrus) & 1600 \\
& \\
\hline
\end{tabular}

* In relation to the sensitivity of human erythrocytes (represented by 100 ). Suspensions ( $1 \%$ ) of mammalian erythrocytes were tested at $37^{\circ} \mathrm{C}$ and those of fish erythrocytes at $15^{\circ} \mathrm{C}$. The means of at least three tests are given.

\section{Comparison of the action of $\delta$-haemolysin, saponin and Triton $X-100$} on cod and mammalian erythrocytes

Cod erythrocytes were strikingly more sensitive than human or rabbit erythrocytes to the action of $\delta$-haemolysin, but not to saponin or Triton X-100 (table III). Lysis of cod, human and rabbit erythrocytes by saponin or Triton X-100 was independent of temperature (table IV). Lysis of human and rabbit erythrocytes, but not cod erythrocytes, by $\delta$-haemolysin was dependent on temperature.

Comparison of human and fish erythrocytes in respect of sensitivity to $\delta$-haemolysin, as demonstrated by radial diffusion assay in blood agar plates

Plates containing cod or mackerel erythrocytes deteriorated rapidly at $37^{\circ} \mathrm{C}$ owing to the instability of the erythrocytes at this temperature; the plates were therefore incubated at room temperature.

TABLE III

Haemolytic activity of $\delta$-haemolysin, saponin and Triton $X-100$

\begin{tabular}{l|rcc}
\hline Haemolytic agent & \multicolumn{3}{c}{$\begin{array}{c}\text { Activity (HU50 per mg) against } \\
\text { erythrocytes of the stated species }\end{array}$} \\
\hline Cod & Rabbit & Human \\
Delta-haenolysin & 1200 & 300 & 400 \\
Saponin & 80 & 32 & 16 \\
Triton X-100 & 5 & 16 & 10 \\
\hline
\end{tabular}


TABLE IV

Temperature sensitivity of haemolysis by $\delta$-haemolysin, saponin and Triton $X-100$

\begin{tabular}{l|ccc}
\hline Haemolytic agent & \multicolumn{3}{|c}{$\begin{array}{c}\text { Ratio (haemolysin titre at } 37^{\circ} \mathrm{C}: \\
\text { haemolysin titre at } 0^{\circ} \mathrm{C} \text { ) obtained with } \\
\text { erythrocytes of the stated species }\end{array}$} \\
\hline $\begin{array}{l}\text { Cod } \\
\text { Delta-haemolysin }\end{array}$ & Rabbit & Human \\
Saponin & 1 & $>16$ & $>64$ \\
Triton X-100 & 2 & 1 & 4 \\
\hline
\end{tabular}

In cod-, mackerel- and human-blood $(2 \% \mathrm{v} / \mathrm{v})$ agar plates incubated at room temperature, zones of clearing due to $\delta$-haemolysin were visible within $4 \mathrm{~h}$, but required $48 \mathrm{~h}$ to reach their maximal diameters. At $48 \mathrm{~h}$ the zone diameter was proportional to $\log$ haemolysin concentration (fig. 2) and was strikingly dependent on the concentration of erythrocytes in the plates (fig. 3).

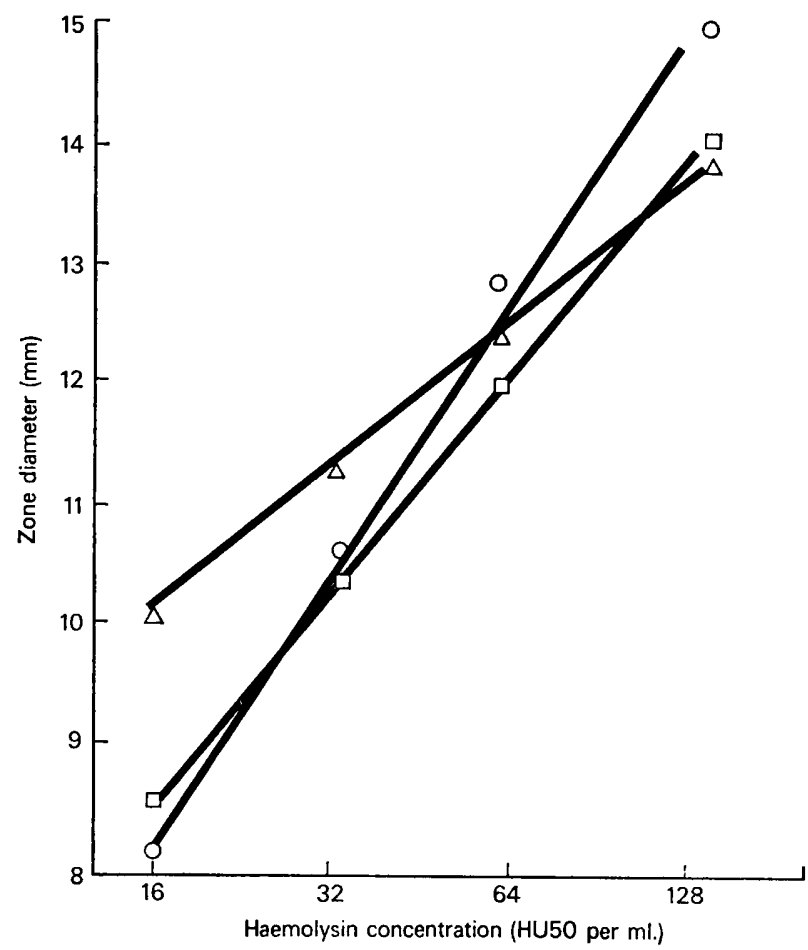

FIG. 2.-Zones of lysis produced by $\delta$-haemolysin in mackerel ( and human $(\square \longrightarrow \square)$ blood agar. 


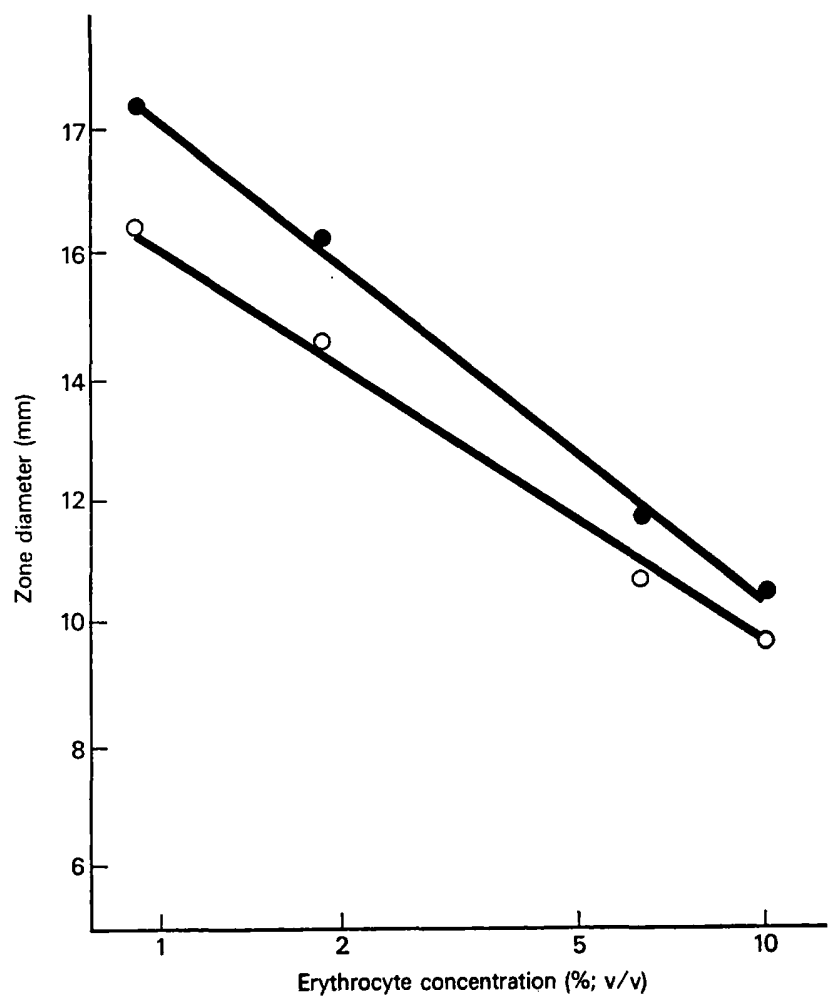

FIG. 3.-Diameters of the zones of lysis produced by $\delta$-haemolysin in agar plates containing different concentrations of cod $(\mathrm{O}-\mathrm{O})$ or mackerel $(-1-\mathrm{O})$ erythrocytes. The measurements were made $48 \mathrm{~h}$ after the addition of $10 \mu \mathrm{l}$ of $\delta$-haemolysin to the plates.

Human, cod and mackerel erythrocytes showed a linear response over the range of $\delta$-haemolysin concentrations tested and although the sensitivities of all three types of erythrocyte were similar, the slopes of the lines varied widely; a doubling of the $\delta$-haemolysin concentration resulted in increases in zone diameter of $2.4,1.9$ and $1.3 \mathrm{~mm}$ for mackerel, human and cod erythrocytes respectively. The slope obtained for human erythrocytes was similar to that found by Kantor, Temples and Shaw (1972) for human blood agar incubated at $37^{\circ} \mathrm{C}$.

Because of the time taken, the quantity of erythrocytes required and the low sensitivity, radial diffusion in fish blood agar would be inferior to a tube dilution method as a means of assaying $\delta$-haemolysin.

Haemolytic zones produced by staphylococci in blood agar-overlay plates

Cod blood deteriorated rapidly at $37^{\circ} \mathrm{C}$ and blood agar plates darkened so quickly that zones of lysis could not be distinguished after overnight incubation. A blood agar-overlay technique was therefore used to detect haemolysin production by staphylococci cultured on nutrient agar. When $5 \%(\mathrm{v} / \mathrm{v}) \mathrm{cod}$ blood agar was used as an overlay on nutrient agar plates previously inoculated with eight strains of $S$. aureus and incubated for $24 \mathrm{~h}$ at $37^{\circ} \mathrm{C}$, all colonies showed 
TABLE V

Zones of haemolysis produced by seven strains of $S$. aureus and one strain of S. epidermidis in blood agar-overlay plates incubated in air or in $30 \% \mathrm{CO}_{2}$

\begin{tabular}{|c|c|c|c|c|c|c|c|c|c|c|}
\hline \multirow{3}{*}{ Strain } & \multicolumn{10}{|c|}{$\begin{array}{l}\text { Haemolytic zones ( } \mathrm{mm} \text { from colony edge to zone edge) produced in agar overlays } \\
\text { containing erythrocytes from the stated species by cultures grown in air (A) or in } \\
\text { air containing } \mathrm{CO}_{2} 30 \% \text { (C) }\end{array}$} \\
\hline & \multicolumn{2}{|c|}{ Man } & \multicolumn{2}{|c|}{ Horse } & \multicolumn{2}{|c|}{ Sheep } & \multicolumn{2}{|c|}{ Rabbit } & \multicolumn{2}{|c|}{ Cod } \\
\hline & A & $\vec{C}$ & A & $\vec{C}$ & A & $\vec{C}$ & A & $\mathrm{C}$ & A & $\mathrm{C}$ \\
\hline NCTC10345 & 1.7 & 0.9 & 0.9 & 0.5 & 0 & 1.6 & $2 \cdot 4$ & $4 \cdot 3$ & $4 \cdot 6$ & $1 \cdot 7$ \\
\hline Wood 46 & $2 \cdot 8$ & 1.4 & $2 \cdot 0$ & 0.4 & 0.2 & 0.2 & $2 \cdot 7$ & 1.6 & 3.4 & $1 \cdot 3$ \\
\hline SM10 & $2 \cdot 3$ & 0.7 & 1.4 & 1.4 & 0 & $2 \cdot 1$ & 2.5 & $5 \cdot 3$ & $4 \cdot 3$ & $1 \cdot 3$ \\
\hline SM14 & $3 \cdot 4$ & 0.8 & $2 \cdot 0$ & $2 \cdot 3$ & 0 & $1 \cdot 8$ & $3 \cdot 8$ & $5 \cdot 8$ & 5.0 & 1.6 \\
\hline BB & $2 \cdot 8$ & 1.9 & $1 \cdot 3$ & $3 \cdot 7$ & $7 \cdot 6$ & $9 \cdot 3$ & $3 \cdot 6$ & $8 \cdot 0$ & $4 \cdot 1$ & $1 \cdot 1$ \\
\hline JK21 & $3 \cdot 3$ & $1 \cdot 3$ & $2 \cdot 1$ & 0.4 & $0 \cdot 1$ & $0 \cdot 2$ & 1.9 & $1 \cdot 7$ & $4 \cdot 0$ & $1 \cdot 1$ \\
\hline SM6 & 0 & 0 & 0 & 0 & 0 & 0 & 0 & 0 & $1 \cdot 2$ & 0.2 \\
\hline SM9 & 0.6 & 0 & 0 & 0 & 0 & 0 & 0 & 0 & $2 \cdot 3$ & 0 \\
\hline
\end{tabular}

clearly defined zones of lysis (fig. 4) that were larger than those produced in human or horse blood agar (table V).

Williams and Harper (1947) and Marks and Vaughan (1950) stated that the yield of $\delta$-haemolysin in culture was greatly increased by an atmosphere containing carbon dioxide. Nutrient agar plates were therefore inoculated by the stab method with the eight staphylococcal strains and incubated in an atmosphere either of air, or of air containing $30 \% \mathrm{CO}_{2}$ before application of the bloodagar overlay. After incubation for $48 \mathrm{~h}$ at $6^{\circ} \mathrm{C}$ the zones of lysis produced in cod or human blood-agar overlays by cultures grown in $30 \% \mathrm{CO}_{2}$ were seen to be smaller than those produced by cultures grown in air (table V). However, inspection of the sheep blood-agar overlays showed that the earlier use of $30 \%$ $\mathrm{CO}_{2}$ either had no effect on lysis or increased the size of the zones. The $\beta$ haemolysin-producing strains, SM14 and BB, produced larger zones of lysis on horse, sheep and rabbit blood-agar overlays if the cultures had been grown in $30 \% \mathrm{CO}_{2}$ instead of in air.

\section{Discussion}

The disadvantages of the earlier use of human or horse erythrocytes for assaying staphylococcal $\delta$-haemolysin were that sensitivity was low and that the possibility of synergism with $\beta$-haemolysin existed. Our findings indicate that erythrocytes from cod are more sensitive and more specific for $\delta$-haemolysin assay than those used hitherto, and that $\alpha$ - and $\beta$-haemolysins have no detectable effect on cod erythrocytes. It is extremely unlikely that the haemolysis of cod 
erythrocytes was caused by an impurity in the $\delta$-haemolysin preparations so far tested. The haemolytic agent was heat stable $\left(100^{\circ} \mathrm{C}\right.$ for $10 \mathrm{~min}$.), was neutralised by normal serum and had properties similar to those reported for $\delta$ haemolysin by several authors (Marks and Vaughan, 1950; Gladstone and Yoshida, 1967; Kreger et al., 1971; Kantor et al., 1972; Heatley, 1977). Moreover, on isoelectric focusing, all haemolytic activity (against cod, human and rabbit erythrocytes) was associated with the single peak of protein that occurred. Fish blood is not as readily available as blood from many mammalian species, but cod blood has been stored satisfactorily for over 1 year in liquid nitrogen, with dimethyl sulphoxide as a cryoprotectant, without detectable deterioration (Chao and Birkbeck, to be published). The use of a single pool of stored blood avoids any complication that might result from variation between different blood samples, although in the limited survey reported here no variations between individuals were noted in terms of the sensitivity of the erythrocytes to $\delta$-haemolysin. Our findings with the blood agar-plate assay agree with those of Kantor et al. (1972). However, the thermolability of cod erythrocytes necessitated considerable care in preparation of blood-agar plates and precluded overnight incubation at $37^{\circ} \mathrm{C}$. It was considered preferable to assay haemolysin by the tube dilution method rather than by radial diffusion in blood agar. In blood agar-overlay plates containing cod blood, the sizes of the zones of lysis were assumed to be a measure of $\delta$-haemolysin production. Contrary to the findings of earlier workers (Williams and Harper, 1947; Marks and Vaughan, 1950 ) incubation in an atmosphere of $30 \% \mathrm{CO}_{2}$ in air depressed the production of $\delta$-haemolysin. Synthesis of other haemolysins was stimulated by growth in $30 \% \mathrm{CO}_{2}$, as evidenced by the larger zones of lysis produced in sheep and rabbit blood-agar overlays by cultures grown in $30 \% \mathrm{CO}_{2}$ than by those grown in air.

Cod and mammalian erythrocytes did not differ significantly in their sensitivity to lysis by saponin and Triton X-100 (table III), but they differed in their sensitivity to $\delta$-haemolysin (table IV and fig. 1). Although more potent, $\delta$-haemolysin resembled in several ways the surface active agents saponin and Triton X-100 in respect of action on cod erythrocytes: lysis was not temperature dependent and it occurred rapidly without lag. Bernheimer (1970) has suggested that when a fixed quantity of a cytolytic agent acts on varying concentrations of erythrocytes, the shape of the dose response curve may reflect the mode of action of the agent. However, different patterns of response were found when $\delta$-haemolysin acted on erythrocytes, indicating either that $\delta$ haemolysin may act in different ways on erythrocytes from different species, or that such experiments in isolation are of limited value in defining the mode of action of a cytolytic agent (Bernheimer, 1970). Current evidence suggests that the action of $\delta$-haemolysin resembles that of certain surface-active agents, namely Triton X-100 and melittin (Bernheimer, 1974; Freer and Arbuthnott, 1976) in producing large "functional holes" in the erythrocyte membrane (Thelestam and Möllby, 1975), and fish erythrocytes may have a specific receptor that facilitates the interaction of $\delta$-haemolysin with the hydrophobic region of the membrane. Recent reports (Low and Finean, 1976 and 1977) of a phosphatidylinositol-specific phospholipase C, distinct from $\delta$-haemolysin, may 
explain previous suggestions that $\delta$-haemolysin is a phospholipase (Wiseman and Caird, 1968; Wiseman, 1975).

The high sensitivity of the cod erythrocyte assay is currently being exploited to investigate the $\delta$-haemolysin in respect of its neutralisation by serum lipoproteins (Whitelaw and Birkbeck, 1976) and its immunogenicity (Birkbeck and Whitelaw, 1976).

\section{SUMMARY}

Suspensions of erythrocytes from certain marine fish (cod, saithe, haddock and mackerel) were 4-16 times more sensitive than human or horse erythrocytes to staphylococcal $\delta$-haemolysin. Cod erythrocytes were lysed rapidly by $\delta$ haemolysin and the titres of haemolysin were independent of the temperatures at which the tests were incubated, over the range $0-37^{\circ} \mathrm{C}$. Fish erythrocytes were not lysed by purified $\alpha$ - and $\beta$-haemolysins and no synergistic action was found between $\beta$ - and $\delta$-haemolysins. In blood agar-overlay plates, the zones of lysis that developed in cod blood agar were larger and clearer than those that developed in human or horse blood agar.

We thank Professor N. Millott, formerly Director of the University Marine Biological Station, Millport, Isle of Cumbrae, for supplying fish blood, Dr D. K. R. Low for supplying purified $\beta$-haemolysin, $\operatorname{Dr}$ A. Kreger for supplying $\delta$-haemolysin and Professor J. P. Arbuthnott for supplying purified $\alpha$-haemolysin and for his encouragement in this work.

\section{REFERENCES}

ARbuthnotT, J. P. 1970. Staphylococcal $\alpha$-toxin. In Microbial toxins, edited by T. C. Montie, S. Kadis and S. J. Ajl, New York and London, vol. 3, p. 189.

Bernheimer, A. W. 1970 . Cytolytic toxins of bacteria. In Microbial toxins, edited by S. J. Ajl, S. Kadis and T. C. Montie, New York and London, vol. 1, p. 183.

BERNHEIMER, A. W. 1974. Interactions between membranes and cytolytic bacterial toxins. Biochim. biophys. Acta, 344, 27.

Bernheimer, A. W., Kwang, S. K., Remsen, C. C., Antanavage, J. and Watson, S. W. 1972. Factors affecting interaction of staphylococcal alpha toxin with membranes. Infect. Immun., 6, 636.

BirkbeCK, T. H. AND Whitelaw, D. D. 1976. Immunogenicity of staphylococcal deltahaemolysin. Proc. Soc. gen. Microbiol., 4, 12.

Davis, B. J. 1964. Disc electrophoresis. II. Method and application to serum proteins. Ann. N.Y. Acad. Sci., 121, 404.

Doery, H. M., Magnusson, B. J., Gulasekharam, J. and Pearson, J. E. 1965. The properties of phospholipase enzymes in staphylococcal toxins. J. gen. Microbiol., 40, 283.

Dulbecco, R. AND Vogt, M. 1954. Plaque formation and isolation of pure lines with poliomyelitis viruses. J. exp. Med., 99, 167.

Freer, J. H. AND ARbuthnott, J. P. 1976. Biochemical and morphologic alterations of membranes by bacterial toxins. In Mechanisms in bacterial toxinology, edited by A. W. Bernheimer, New York, p. 169.

Gladstone, G. P. AND YoshidA, A. 1967. The cytopathic action of purified staphylococcal $\delta$-haemolysin. Br. J. exp. Path., 48, 11.

Heatley, N. G. 1971. A new method for the preparation and some properties of staphylococcal delta-haemolysin. J. gen. Microbiol., 69, 269.

Heatley, N. G. 1977. Production of antibody to staphylococcal delta-haemolysin in the rabbit. Br. J. exp. Path., 58, 400. 

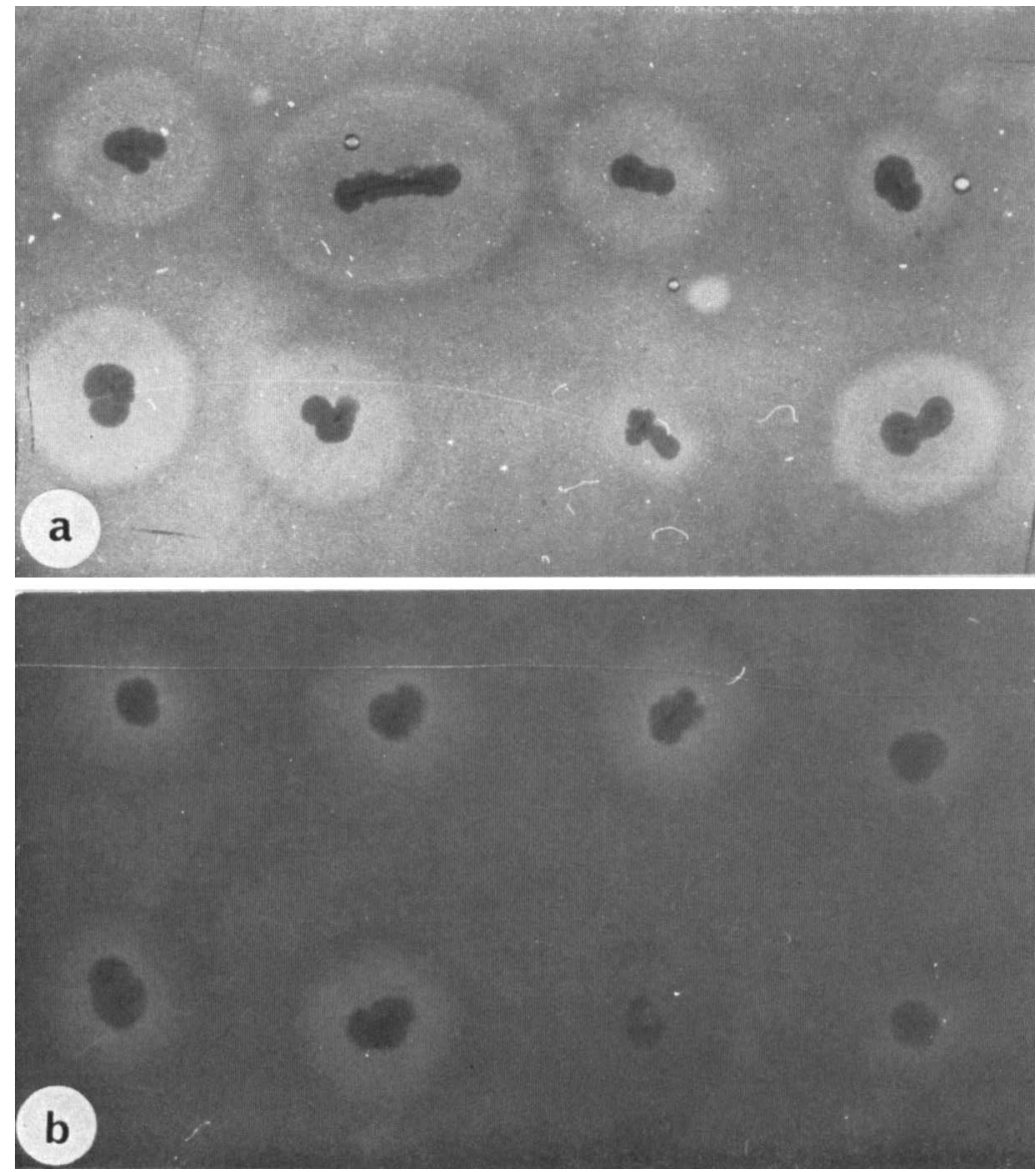

FIGs. $4 a$ and $4 b$.-Zones of lysis in blood agar-overlay plates. The overlays contained $(a)$ cod erythrocytes, and $(b)$ human erythrocytes. The staphylococcal strains in figs $4 a$ and $4 b$ were: top row (left to right) Wood 46, SM14, JK21 and SM9; bottom row (left to right) SM10, BB, SM6 and NCTC10345. 
Hodgins, H. O. AND Ridgway, G. J. 1964. Preservation of trout and salmon erythrocytes for blood typing by freezing with dimethyl sulphoxide. Nature, Lond., 201, 1336.

Kantor, H. S., Temples, B. and Shaw, W. V. 1972. Staphylococcal delta-hemolysin: purification and characterization. Archs Biochem. Biophys., 151, 142.

Kreger, A. S., Kim, K.-S., Zaboretzky, F. And Bernheimer, A. W. 1971. Purification and properties of staphylococcal delta-hemolysin. Infect. Immun., 3, 449.

Low, D. K. R. AND FreER, J. H. 1977. The purification of $\beta$-lysin (sphingomyelinase C) from Staphylococcus aureus. FEMS Letters, 2, 139.

Low, M. G. AND FINEAN, J. B. 1976. The action of phosphatidylinositol-specific phospholipases C on membranes. Biochem. J., 154, 203.

Low, M. G. AND FineAN, J. B. 1977. Modification of erythrocyte membranes by purified phosphatidylinositol-specific phospholipase C (Staphylococcus aureus). Biochem. J., 162, 235.

Marks, J. ANd Vaughan, A. C. T. 1950. Staphylococcal $\delta$-haemolysin. J. Path. Bact., 62, 597.

McNiven, A. C., Owen, P. And Arbuthnott, J. P. 1972. Multiple forms of staphylococcal alpha-toxin. J. med. Microbiol., 5, 113.

MölLBY, R. AND WADSTRöM, T. 1971. Separation of gamma-hemolysin from Staphylococcus aureus Smith 5R. Infect. Immun., 3, 633.

Nelson, G. J. 1967. Lipid composition of erythrocytes in various mammalian species. Biochim. biophys. Acta, 144, 221.

Reisfeld, R. A., Lewis, U. J. AND Williams, D. E. 1962. Disk electrophoresis of basic proteins and peptides on polyacrylamide gels. Nature, Lond., 195, 281.

Rennie, R. P. AND Arbuthnott, J. P. 1974. Partial characterisation of Escherichia coli haemolysin. J. med. Microbiol., 7, 179.

TALBOT, P. AND CAIE, I. S. 1975. A horizontal trough apparatus for isoelectric focusing. In Isoelectric focusing, edited by J. P. Arbuthnott and J. A. Beeley, London, p. 74.

ThelestaM, M. AND MöllBY, R. 1975. Determination of toxin-induced leakage of differentsize nucleotides through the plasma membrane of human diploid fibroblasts. Infect. Immun., 11, 640.

Thelestam, M., Möllby, R. AND Wadström, T. 1973. Effect of staphylococcal alpha-, beta-, delta- and gamma-hemolysins on human diploid fibroblasts and HeLa cells: evaluation of a new quantitative assay for measuring cell damage. Infect. Immun., 8, 938.

Whitelaw, D. D. AND BirKBeCK, T. H. 1976. Neutralisation of staphylococcal deltahaemolysin by human plasma lipoproteins. Proc. Soc. gen. Microbiol., 4, 12.

Williams, R. E. O. AND HARPER, G. J. 1947. Staphylococcal haemolysins on sheep blood agar with evidence for a fourth haemolysin. J. Path. Bact., 59, 69.

Wiseman, G. M. 1975. The hemolysins of Staphylococcus aureus. Bact. Rev., 39, 317.

Wiseman, G. M. ANd CaIRD, J. D. 1967. The nature of staphylococcal beta hemolysin. I. Mode of action. Can. J. Microbiol., 13, 369.

Wiseman, G. M. AND CAIRD, J. D. 1968. Phospholipase activity of the delta-hemolysin of Staphylococcus aureus. Proc. Soc. exp. Biol. Med., 128, 428. 